Research Article

\title{
Identification of Hispanic English Language Learners in Special Education
}

\author{
Gail I. Becker (iD) ${ }^{1}$ and Aaron R. Deris (iD) ${ }^{2}$ \\ ${ }^{1}$ Department of Special Education, Monmouth University, West Long Branch 07764, NJ, USA \\ ${ }^{2}$ Department of Special Education, Minnesota State University, Mankato, Mankato 56001, MN, USA \\ Correspondence should be addressed to Gail I. Becker; gibecker@monmouth.edu
}

Received 29 August 2018; Accepted 10 April 2019; Published 19 May 2019

Academic Editor: Gwo-Jen Hwang

Copyright (C) 2019 Gail I. Becker and Aaron R. Deris. This is an open access article distributed under the Creative Commons Attribution License, which permits unrestricted use, distribution, and reproduction in any medium, provided the original work is properly cited.

\begin{abstract}
Overrepresentation of English language learners (ELLs) in special education is a current problem. Urban school professionals indicated that inappropriate placement is linked to a multiplicity of factors. Scarce data exist regarding the relationship between school professional efficacy beliefs, the availability of bilingual programs and personnel for ELLs, and successful academic outcomes. School employees are still confused about the proper placement of English language learners (ELLs). What is enough time to acquire a second language and learn with success? Without other substantial program choices, children are referred to special education. Furthermore, many students in need of special education may be overlooked and remain in ESL programs for their entire school career. The aim of this study was to identify the role staff member's efficacy plays in the proper determination of an ELL with a language difference or disability. Child study team (CST) members $(n=14)$ working with a large Hispanic ELL population participated in semistructured interviews to determine the role their efficacy beliefs exert during assessment of linguistically diverse students. Overwhelmingly, staff members noted that they did not feel competent when making decisions regarding ELLs. Therefore, staff members placed the children into special education each time. The practice implications come from the prominent themes that include significant in-district professional development on second language acquisition, facilitation of second language through use of first language through bilingual staff, and committed bilingual programs to meet ELL needs. Additionally, universities must provide coursework that furthers second language acquisition theories and strategies for all teacher candidate programs.
\end{abstract}

\section{Introduction}

The population of American-born children in mixed-status families with immigrant parents and citizen children has grown from 2.7 million in 2003 to 4 million in 2008 [1]. Many come from Spanish speaking households and are English language learners [2]. Currently, one in 12 young children is Hispanic and concentrated in 24 states located throughout the United States [3]. By the mid-twenty-first century, the Latino school-age population will be the largest racial and ethnic group in United States public schools [4].

Children who have limited English proficiency may feel defeated when thrust into mainstream classes where subject matter is rendered meaningless because instruction is taught with little to no first language support [5]. School professionals misguidedly assume that the ability of English language learners (ELLs) to converse in basic English is an indication of one's ability to learn academic content on grade level [6]. Political intervention and legal mandates have resulted in the implementation of various bilingual programs, but the problem of overrepresentation of English language learners in special education programs continues [7-11].

States have failed to create program standards for early intervention bilingual programs at the preschool level [12]. Therefore, students must wait for kindergarten or first grade to begin receiving services, if any, from the school district's bilingual department. When intervention is delayed and students fail to become successful, teachers and other school professionals are left with limited options and view this lack of academic success negatively [13]. These students are often perceived as learning disabled due to limited or improper 
opportunities to learn [14]. School professionals erroneously refer ELLs to the special education department for an evaluation to potentially classify the student as disabled [15-17]. Once referred to the child study team, the student has a "greater than $50 \%$ chance" (p. 175) of being identified as disabled [18].

School professionals, who lack the appropriate understanding of testing tools, remain unprepared to properly assess and evaluate ELLs, thus complicating the challenge of proper placement [19-21]. Students from culturally and linguistically diverse backgrounds are overrepresented in special education, expressing the need for teachers and administrators to become culturally competent [9]. Additionally, school professionals lack knowledge of second language acquisition and are incapable of determining the presence of a language difference versus a learning disability, compounding the problem of improper placement and overrepresentation of ELLs in special education programs $[6,15,22,23]$.

Bandura [24] posited that a school professional's perception of their personal efficacy is directly related to their practices. Therefore, if an individual believes they are capable of competently completing an assignment, these beliefs indicate high levels of motivation and allow us to predict subsequent practices. Conversely, if a school professional conceals or is unaware of their inability to perform a task, according to Bandura's social cognitive theory, they will do only what they know, allow someone else to address the problem, work within a group for a desired outcome, or avoid the task [25]. Bandura's social cognitive theory is very apropos to the way child study teams and teachers function within a school setting whereby both individual and collective decision-making exists.

The purpose of this qualitative study was to understand how school professionals' personal and general efficacy beliefs when assessing ELLs and availability, or lack of, proper program options may affect the overrepresentation of Hispanic ELLs in special education. When children are successful in an environment where a language difference is acceptable, they are not erroneous and often in violation of state and federal guidelines, targeted for special education evaluation, assessment, and subsequent labeling by school professionals $[13,14]$. This qualitative study extends the research on a very current topic, overidentification of bilingual children in special education, and adds the input of speech pathologists, social workers, and learning disabilities teacher-consultants as members of this decision-making process. This research is important to all school professionals because staff members should be knowledgeable, confident, and empowered when making such important educational decisions [26]. Many will see that improper and unwarranted restrictive programs and policies are detrimental to students [27].

\section{Method}

2.1. Participants. Eighteen child study team members initially volunteered to be interviewed in this study after responding to a survey distributed to all 38 child study team members in the district. Fourteen were interviewed after it was determined that saturation of themes was evident. There are nine schools in the district; seven schools house preschool classrooms. There were three social workers, four learning disabilities teacher-consultants, four speechlanguage pathologists, and three school psychologists. All participants had a minimum of five years of experience and as many as 24 years in education. All were female and Caucasian. Two felt that their knowledge of Spanish was helpful personally, but not for assessment purposes (see Appendix B) (Figure 1).

2.2. Materials and Procedure. Both a survey and in-depth interview process were used to retrieve information in this study, with interviews taking place at mutually convenient locations and times. The first measure, a survey adapted from the Speech-Language Services to Bilingual/Bicultural Individuals (SLSBBI) originally developed by Kritikos for a mixed-method study, was used to capture the efficacy beliefs of school professionals working with ELLs [15]. The survey was disseminated to all child study teams and speech/ language pathologists $(n=38)$ who assess and evaluate ELLs to determine their personal and professional efficacy beliefs and knowledge regarding ELLs, language acquisition, and testing and evaluation.

The survey was used prior to the interview. It provided the context of the study to the participants and provided basic demographics of the participants such as position in district and spoken language(s). The survey also led to a volunteer pool of interview participants and highlighted initial themes or talking points for the subsequent interview. This questionnaire was slightly modified to encompass the scope of this study, specifically to include a broader range of school professionals than Kritikos' original speech-language pathologist only.

Semistructured in-depth interviews were conducted to provide a deeper understanding of school professionals' perceived needs and efficacy beliefs regarding proper placement of ELLs. The interview questions were consistent with the context of the original survey and provided a more personal approach. Themes that surfaced from the interviews were analyzed, interpreted, and reported. Transcripts were reviewed by the interviewee for accuracy before being reported. The researcher assured all participants that there were no incorrect answers. The interview questions varied and were designed to retrieve both short, quick answers as well as long reflective responses (see Appendix A). The long interview (60-90 minutes) provided an informal atmosphere.

2.3. Procedure. The survey was disseminated electronically to 38 decision-makers in the district that included speechlanguage pathologists, learning disabilities teacherconsultants, and social workers. Of the 38 surveys disseminated, 27 surveys or $61 \%$ were returned. Of the 27 returned surveys, 18 individuals volunteered to participate in the long interview; however, only 14 child study team (CST) individuals were interviewed when saturation of themes 

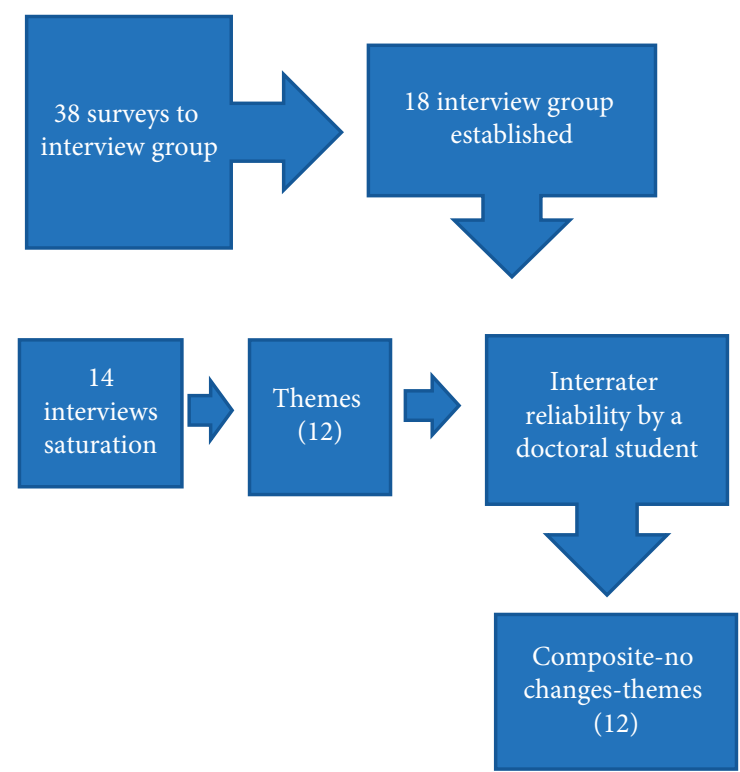

FIGURE 1

became evident. As the surveys were returned, interviews were scheduled with those volunteering to be interviewed.

The semistructured long interview was conducted at mutually agreed upon neighborhood locations such as the local library. The interviews often lasted between one to two and half hours in length. Depending on participant preference, interviews were either recorded with a tape recorder or done by longhand. Broad ideas and themes were drawn from these data and interpreted to reflect the new information.

\section{Results}

3.1. Themes. The themes that emerged from the data were as follows:

(1) ELLs need time to develop English language skills

(2) Importance of fostering home language in school

(3) Need for staff to have cultural competency skills

(4) Importance of family involvement

(5) Overidentification in special education

(6) Underidentification in special education

(7) Need for bilingual personnel in the classroom

(8) Need for training in second language acquisition

(9) Need for collaboration in eligibility decisions fostering global consideration

(10) Need for tests that are reasonable for Spanish students and bilingual students

(11) Advantages of bilingualism

(12) Need for bilingual/dual language programs that are well thought out and planned

School practitioners' descriptions of their personal and general efficacy beliefs were directly related to personal experience. Although most respondents felt less than competent, proffering the most common response of not sharing the same language with the student, those that shared a similar duality, such as not having been born in the United States or having some degree of fluency/ comprehension of Spanish, felt more competent when assessing and therefore were not quick to determine a potential disability as follows:

I understand why it is difficult for teachers in the classroom when students are not talking. However, there are many things that must take place before a decision to determine disability occurs. I like to think that I look at the whole child. He or she is a part of a family. What do the parents think? Do they have concerns? Can the child speak the native language? How long has the child been in the country? What is the education level of the parents? What is going on with his siblings? Is there a program available in the district to transition the student to English? (SW 1)

The biggest problem, as I see it, is not giving children enough time and classifying too early. Not giving them enough experience to acquire the language. Remember, they are with us for only a portion of their day. And then they are going home to their native language. These children oftentimes come to us as preschoolers not even proficient in their native language yet. (LDT-C 4)

However, most respondents felt their self-efficacy is compromised even though they consider themselves good at what they do. Respondents also stated that the use of a translator or interpreter is often stressful.

When I have to use an interpreter to speak to a parent, I already begin the process feeling diminished control of the situation. Now when I conduct a psychological assessment and a person is translating the material, I am not given the opportunity to add some subjectiveness (SIC) that may be important to the decision. I don't speak Spanish and therefore, feel less effective. (School Psychologist 3)

Several staff members directly involved with an indistrict dual language preschool program saw diverse benefits from the program for all children; however, each also saw the need for improvement and offered very similar responses.

The Dual Language Program is a wonderful program. It was really heartwarming to see because as 3-year-olds, many of these babies were not speaking. As 4-year-olds, you don't want to tell them to be quiet, but they were just like Chatty Kathy, they go--both languages. They just took off. It was really very nice. (LDT-C 1)

The program was consuming and confusing. It seemed less than ideal for such young children at three years of age to move between classes to their Spanish or English world. I saw a big difference with the 4-year-old dual language program. The program kept moving, but the ability of the children didn't always catch up quite as fast. (School Psychologist 1) 
The dual language program as it was originally conceived by the now retired bilingual supervisor ran true to its philosophical foundations for the 2009-2010 school year and somewhat less in 2010-2011 school year. After those two years and a third supervisor, the program no longer exists. The school practitioners interviewed stated that the parents really wanted the program to continue. When asked what they believed was the reason for this change, it was unanimously stated, "The vision of the first supervisor." The verbatim responses speak more to needed administrative supports and provide insight into perceived barriers to properly assess ELLs.

The word "barriers" during the interview had a broader than anticipated meaning. For example, school professionals asked "Do you mean if the family is here legally?" Although this concept had not been considered as a component of assessment, occasionally it was discovered, through the interview responses, that a family's legal status in the country may prohibit or hinder cooperation from the family or the educator. Conversely, if a family intimated somehow that they would not be living here much longer that similarly presented a dilemma for the school professional. The respondents were encouraged to interpret the word "barriers" however they chose. However, the general responses could be categorized into two groups, school professionals' self-efficacy and school professional's tangential needs.

I have come to learn that we need to give ELLs time to develop. We need to allow them that silent period of time to take it all in, be exposed to it, digest it, and the new language will come through. Many of the parents do not speak English; the children go home to their native language. At meetings, a bilingual coworker would tell parents, "We want your children to speak in English in school so you really shouldn't"... and that's completely incorrect, completely incorrect. We should want children to maintain their native language while developing their second language. The biggest difficulty comes from everyone having philosophical beliefs of what is correct. (LDT-C 3)

The relationship between culture and language is strong, very strong. I believe that your experiences in language are based on your culture. For example, what's up with this selective mutism diagnosis of 3-year-old ELLs who have two emergent languages? Should we really believe they have psychological issues? Or rather, should we explore the cultural aspects of what a child is taught at home? (LDT-C 2)

The dual language preschool program was a great addition, but it would not be helpful in the upper grades. Students enter middle and high school with zero English. Now that's a real challenge. Keeping sheltered immersion is helpful, providing summer programs too. Yet, the need to move them out the door quicker than they are ready doesn't make sense to me. I worry about the number of dropouts and the threat of gang membership when children have no options. (SW 3)
I am not confident in my knowledge of second language acquisition. With the way the district has changed, even general education teachers should be provided training on this topic. (LDT-C 2)

Face it-there is not enough in place in each classroom to facilitate enough infusion of the native language into the program. They are going to acquire English but they are not going to get to the level they need to be as English learners until you can assess accurately what they know in their own language. And build on that. This goes back to the other question-when you look at economically challenged areas, it is not just a language barrier, it's economical, and it's the education level of the parents, the age of the parents. (SLP 1)

I have evaluated many ELLs. There are more barriers than just language. A lot of times, children are middle school or high school age, but did not go to school in their previous country. So not only do they not have the English language, they don't understand any foundational skills. The problem is the curriculum the district uses for middle school or high school does not teach at the level they are at-possibly kindergarten/first grade. Because they did not go to school, they cannot understand "add two plus two" even if spoken in Spanish. How can you call them special education if they haven't been taught ever in their life? (School Psychologist 1)

Themes emerged indicating need for supports as follows:

(i) More dual language/bilingual preschool programs:

The dual language program was an option and a valuable one at that. Although I do not teach, I often found myself saying that maybe the program will be expanded next year so that more children will have this opportunity. I felt better about my decisions not to evaluate a child exhibiting a confirmed language difference with a possible language disorder if he could get into a program where we could see if a potential disability existed in the native language as well. (SW 2)

(ii) Need for more bilingual speech-language pathologists and bilingual child study team members:

You need to use assessments in their language and in English and see where their strengths and weaknesses are before anything else is done. Gather the baseline data. This is the ethical thing to do. This is not done all the time. If we test a child in English and the child speaks Spanish, well what can we expect? (School Psychologist 2)

(iii) More information on second language acquisition:

I think because I went to an in-state college and the needs are higher here, my graduate program was very culturally involved. I did have a bilingual assessment course and hands-on assessment in the classroom as part of my practicum, but I never had a class on second language acquisition. I do not feel competent making a decision 
regarding a language disability versus a language difference without consultation with a trained bilingual psychologist or learning consultant. (School Psychologist 3)

(iv) Preservice experience with ELLs or if not possible, then district mentor program that requires observation in bilingual classes for novice teachers:

You cannot do everything in Spanish because you want them to learn English at the same time. Teachers will talk all the time about the student's behaviors, "They cannot follow directions." This is all language-if you don't understand, you're going to have behaviors. If more preservice staff had the ability to see bilingual classes in action and to work with ELLs, they would be better able to address the needs of the children. (SLP 3)

\section{Discussion}

More research is needed to explore the multiplicity of causes of disproportionate identification of CLD students [28, 29]. This study's rich textual descriptions and verbatim responses allow the reader to feel the experiences through the words of the school professionals and begin to elucidate true experiences of a very complex problem. None of the participants were cavalier about a pending classification of a disability. In fact, their words indicated that recent evaluations were being conducted with more interest in the child's first language. This was not always found to be true in prior research $[23,30]$. Hence, decisions are now being made with greater empathy and legality, and this self-efficacy made many of the school professionals happier.

Certain ethnic and racial categories of students appear to be overidentified or underidentified $[14,31]$. The disproportionality of ELLs in special education placement was explored in Arizona [29]. The researcher wanted to know whether patterns or predictors existed within district characteristics, such as the number of teachers with ESL certificates or socioeconomic status of the student would increase the likelihood of special education placement relative to their Caucasian peers. Also posited was the lack of appropriate opportunity to learn within the state mandated English-only curriculum. Using a relative risk ratio, the results indicated that ELLs were more likely to be identified as mentally retarded or as having a specific learning disability disproportionate to their Caucasian peers within many districts across the state. The author presented the literature that reflected findings that many teachers refrain from referring young ELLs in the primary grades. However, in third grade, when reading becomes a content-driven skill, the overrepresentation begins. This 8 year study used existing data that reflected the number of ELLs in special education, their disability, and placement categories relative to their Caucasian peers. Of significance, $91 \%$ of the students identified as ELLs spoke Spanish. More studies are needed to examine causes within the identification process and patterns of representation within states suggesting that one factor cannot predict disproportionality [29].
Other researchers agree that contributing factors to disproportionality are inconsistent identification, assessment, and state-to-state eligibility criteria for special education categories $[8,10,32]$. These variations influence the type and quantity of children classified in the more restrictive programming [14]. Another issue rests with the child study teams who lack training and experience when making decisions for ELLs [23]. Disproportionality may also be due to bias and discrimination in the assessment tool and/or in the tester [33]. Guiberson [34] conducted a literature review to determine if Hispanic children are disproportionally represented in special education. Focusing on patterns of representation and implications for school professionals, Guiberson determined that overrepresentation is not a national trend but occurs at the local level and varies state to state and district to district. Patterns of disability category showed more Hispanics identified as learning disabled or speech-language impaired with increasing numbers in Grades 6-12 [34]. The evaluation of a linguistically diverse student is complicated for many reasons as discussed [18]. Furthermore, even if bias was removed within the testing instruments, the testing specialists, and the tests addressed English learners, children potentially in need of special education services would still be subjected to the various definitions and eligibility requirements within each individual state [35].

Disproportionate representation of ELLs can be a result of factors "outside the student and unrelated to the presence of a disability per se" [29]; p. 331. The 12 consistently agreed upon themes that were illuminated from the data analysis indicate that many forces work in tandem to cause disproportionality. Therefore, from this research, it was apparent that school professionals wanted more training in topics that affect CLD students to include testing and second language acquisition, believe cultural competence of the entire staff is critical, need more bilingual CST members, and lastly believe bilingual program options for ELLs help decision-makers be more effective.

This current study and studies in the past $[28,29,36]$ have shown the need for better professional development. If administrators wish to enhance the use of research-based teaching strategies such as response to intervention, the training needs to draw a connection between the information and how it can be implemented in the classroom [37]. Lastly, even Latino/Latina teachers who have normal psychocultural factors resulting from acculturation and ethnic identity in a predominately Caucasian environment will continue to need the same professional development as their non-Latina/Latino colleagues [38].

Similarly, universities should be preparing preservice teachers to educate students from CLD backgrounds. Many interviewees had not heard of the silent or nonverbal period of second language acquisition and became further confused when the term "selective mutism" as a psychological disorder took on some popularity in the district. Knowledge of second language acquisition will help school professionals more accurately discern the difference between a disability and a language difference during this learning period $[39,40]$. 
The findings in this study provide evidence that school professionals feel more effective when they have more bilingual program options. Krashen [41] recommended that schools provide "aural comprehensible input" (p. 7) within context using movement, pictures, and commands. A preschool classroom provides a naturalistic environment for language to be learned as part of the day-to-day instruction. However, when bilingual programs did not exist at the preschool, many children were deemed unsuccessful, and one respondent stated, "So off to special ed." Several respondents liked aspects of the dual language preschool program from its inception, but once the program was dissolved, the respondents believe that at a minimum, ELLs should have the availability of a bilingual environment whether it is the instructional assistant or the teacher who is bilingual. They also felt that parents were more likely to be supportive if Spanish was spoken in the classroom. These findings are similar to [42]. The authors conducted a comparison study of the dual language program and an English immersion program at the preschool level. The authors found that Spanish speakers had large gains in Spanish receptive language and Spanish language development improved for both ELLs and English-speaking children; however, no significant differences were found on English language measures for any group. Obviously, these authors saw a need to explore the potential of improving native language and the need of second language acquisition for English speakers. However, the greatest distinction in the current study lies in how children will be judged early on in their school careers and the likelihood that Hispanic children who cannot speak English well will be determined to be unsuccessful or disabled as in [29] study. Second language development varies among children with many reaching oral proficiency long before academic proficiency [43]. Some educators have voiced their concern about the federal requirements within NCLB that require ELL students to take the state tests in English reading and language arts within three years after entering the school system [44]. This predetermined language acquisition time fails to acknowledge the differences among children in reaching overall language competency. The test scores also fail to indicate whether a low score was due to English proficiency or lack of knowledge in the content area [21].

Respondents also conveyed the need for bilingual personnel on child study teams and in the classroom. This concern and the shortage have been addressed in many studies $[15,22,29,34]$. To expect future qualified bilingual staff to move to America from a Spanish speaking country shows no urgency by our country's educational leaders. Serious language programs similar to how Europeans and Asians learn English should be implemented.

The barriers that were expressed during the interviews included legal resident status, financial supports to include staff and curriculum, and observation/evaluation supports from administrators. Administrators have indicated that they feel unprepared to help teachers with special education assessment and CLD students [45]. These concerns may mean that preservice leadership programs, similar to preservice teacher programs, must expose the school leaders to matter beyond the general education classroom if decisionmakers in the schools are to feel supported.

The most surprising finding was the unanimous need for cultural competency of the staff. Although important, it was not expected that so many in an urban area believed a lack of cultural competency is what leads to poor decisions and a lower self-efficacy. The respondents were very sure of the connection between language and culture. Therefore, if school districts are designing professional development programs, they should consider programs that expose teachers to ways cultural competency is developed. Not only does cultural competency includes racism and bias, but also it includes ways to value the similarities and differences. Preservice teachers may benefit from coursework; however, inservice teachers may need coaching from a bilingual teacher on teaching strategies for ELLs [34, 46, 47]. This finding may mean that more bias exists with this demographic than originally assumed and that many school professionals determined was necessary to mention.

\section{Implication for Special Education}

When school districts fail to provide adequate programs for ELLs, the school professionals, through default, refer the now struggling ELLs to the special education department for evaluation by the child study team $[14,34]$. Yet, there is no inherent reason why second language learners should receive special education services more than their monolingual peers [16]. The inappropriate placement of ELLs into restrictive exclusionary special education programs is in violation of state and federal guidelines [15]. In response, amendments to the Individuals with Disabilities Education Improvement Act [48] have strengthened nondiscriminatory mandates but to no avail [10]. Additionally, young Hispanic children have limited access to early intervention services and are least likely to be enrolled in private preschool at age three if public school preschool does not exist [3, 7]. High-quality preschool programs supported with primary grade interventions are needed [9]. Unfortunately, many states remain unprepared to provide substantive early intervention bilingual preschool programs that reflect the needs of children currently in their school districts [12]. Instead, schools are providing culturally unresponsive interventions [7]. A twofold effect occurs when the curriculum becomes comprehensible and tailored to each student's need; teacher's expectations of student performance increases, and students become actively engaged in learning [49]. Therefore, when students appear successful, school professionals are not being asked to consider special education placements $[10,50]$. Furthermore, inappropriate labeling is discriminatory and has been correlated to decreased outcomes during and after the school years [51]. Given these persistent variations, underrepresentation, overrepresentation, and misidentification of certain groups may lie in the hands of the assessment and the evaluator. Thus far, there appears to be a gap in the literature about how ELLs' language assessments are administered, by whom, and whether an informal and formal multimethod approach is consistently applied [52]. 


\section{Limitations}

The limitations for this study include self-reported data in response to the open-ended questions in the survey or during the interviews. Self-reported data pose a limitation because people want to give the socially correct answer even when they know the research is conducted in an anonymous format [53]. Additionally, the participants of the study are limited to an urban northeast area. Furthermore, the school professionals are those involved in child study team decisions or those considered ex-officio members of CST. Lastly, the adult participants are all female. Therefore, the current study will not compare adult participant responses by gender. Thus, information gathered may only be considered reflective of female school professionals' perspectives. The delimitation for the current study is the restriction of school professionals to one urban northeast school district. Inferences will reflect one district only. Lastly, it is possible that Spanish speaking bilingual employees may have believed themselves to be more efficacious.

\section{Future Research}

The findings of this study have provided a qualitative perspective of lived experiences that strengthen the need for recruitment of bilingual school professionals, continued inservice training and preservice experiences for school professionals with culturally and linguistically diverse students [22, 36, 46]. Additionally, professional development in topics such as second language acquisition, assessment of ELLs, cultural competency, and lastly bilingual programs at the preschool level provide options for ELLs and school professionals [5, 13, 28, 29, 54, 55]. Furthermore, this study may raise school professional's awareness for ELLs who legitimately require special education services and the need for accurate unbiased identification. School professionals will have greater confidence making a decision within the continuum of special education services to bilingual education or general education once the mandated IDEA $o p$ portunity to learn in a regular education classroom has been fulfilled $[48,56]$.

The research findings of this study supported previous research on professional development and preservice and inservice training. Furthermore, the overwhelming need for cultural competency training in addition to second language acquisition must be taken seriously. The qualitative findings from this research triangulated the quantitative findings regarding the effects of a preschool dual language program by Barnett et al. [42]. However, more research continues to be necessary on this topic as this demographic grows.

Although this study addressed school professionals' efficacy beliefs and its effect on overidentification of ELLs in special education, it is imperative that the findings be presented in a balanced manner. Therefore, although the argument for overidentification is strong, future research should also consider the underidentification of ELL students, who truly are disabled, in an effort to find effective ways to quickly and accurately identify those students who are disabled. Similarly, with language always a monumental part of the equation, future research should address means of identification of gifted ELLs that puts less emphasis on language in the entrance process. If this were possible, then equal educational access may become a reality. "Research must attend to the factors in general education systems that contribute to disproportionality, as it is not a problem inherent in the special education system, but rather it is a product of education as a broad cultural practice" [29]; p. 330. Lastly, the monitoring or tracking of ELL student's success rates as they outgrow one program but still require supports is worthy of further research as a means to provide appropriate opportunity to learn.

\section{Appendix}

\section{A. Semistructured Interview Questions}

Semistructured interview questions are as follows:

(1) Are you aware of any perceptions about disabilities associated with the Hispanic culture? Please explain.

(2) How do you know they exist?

(3) What are your thoughts about working with culturally and linguistically diverse students and their families? What issues arise?

(4) In your opinion, what is the relationship between culture and language?

(5) How, if at all, does the Pilot Dual Language Program address this?

(6) When should a preschooler be classified?

(7) Have you ever evaluated an ELL for a gifted program?

(8) How often have you assessed or been asked to evaluate even informally an English language learner?

(9) What do you believe is necessary to assess the academic and language skills of ELLs?

(10) Are there any additional challenges you confront when assessing an ELL?

(11) What prerequisites do you see as vital to assessing ELLs?

(12) Are there any ethical issues?

(13) What do you think contributes to the misidentification and overrepresentation of English language learners in special education programs?

(14) What factors determine placement of an ELL into a school program?

(15) Tell me about your experience with using an interpreter?

(16) What are the drawbacks and advantages?

(17) How confident are you regarding your knowledge of second language acquisition?

(18) Tell me about coursework or inservice training you have received regarding culturally and linguistically diverse students 
(19) Do you think this specialized training would help you?

(20) What do you know about second language acquisition?

(21) Do you feel competent assessing and making a decision regarding a language disability versus language difference?

(22) How has working with ELLs changed over the years?

(23) What supports do you need?

(24) Do you think there are barriers that are beyond your control?

\section{B. Participant Information}

Participant information is as follows:

\begin{tabular}{lcccc}
\hline Position & Age & Race & Sex & $\begin{array}{c}\text { Years of employment } \\
\text { in-district }\end{array}$ \\
\hline SW 1 & 35 & Caucasian & Female & 7 \\
SW 2 & 36 & Caucasian & Female & 10 \\
SW 3 & 42 & Caucasian & Female & 18 \\
LDT-C 1 & 56 & Caucasian & Female & 25 \\
LDT-C 2 & 36 & Caucasian & Female & 7 \\
LDT-C 3 & 50 & Caucasian & Female & 27 \\
LDT-C 4 & 37 & Caucasian & Female & 14 \\
SLP 1 & 29 & Caucasian & Female & 6 \\
SLP 2 & 48 & Caucasian & Female & 20 \\
SLP 3 & 47 & Caucasian & Female & 21 \\
SLP 4 & 29 & Caucasian & Female & 6 \\
Psych 1 & 28 & Caucasian & Female & 5 \\
Psych 2 & 53 & Caucasian & Female & 22 \\
Psych 3 & 34 & Caucasian & Female & 11 \\
\hline
\end{tabular}

\section{Data Availability}

The qualitative data used to support the findings of this study are included within the article.

\section{Ethical Approval}

This study was approved by the human subjects' committee at Northcentral University. The study was conducted with the human subjects' understanding and consent.

\section{Conflicts of Interest}

The authors declare that there are no conflicts of interest regarding the publication of this paper.

\section{Acknowledgments}

This research article was based on the dissertation completed by the first author. The dissertation was completed at Northcentral University in 2012.

\section{References}

[1] J. S. Passel and D. Cohn, A Portrait of Unauthorized Immigrants in the United States, Pew Hispanic Center, Washington, DC, USA, 2009, http://pewhispanic.org/files/report/107.pdf.

[2] J. S. Passel, The Size and Characteristics of the Unauthorized Migrant Population in the U. S.Pew Hispanic Center, Washington, DC, USA, 2006.

[3] D. Hernandez, Young Hispanic Children in the U.S.: A Demographic Portrait Based on Census 2000, Report to National Task Force on Early Childhood Education for Hispanics, Arizona State University, Tempe, AZ, USA, 2006.

[4] R. Allen, "Preparing Latino students for college success," Education Update, vol. 51, no. 8, pp. 1-2, 2009.

[5] V. L. Estrada, L. Gomez, and J. A. Ruiz-Escalante, "Let's make dual language the norm," Educational Leadership, vol. 66, no. 7, pp. 54-58, 2009.

[6] D. Johnson, How Myths about Language Affect Education: What Every Teacher Should Know, University of Michigan Press, Ann Arbor, MI, USA, 2009.

[7] W. J. Blanchett, J. K. Klingner, and B. Harry, "The intersection of race, culture, language, and disability," Urban Education, vol. 44, no. 4, pp. 389-409, 2009.

[8] R. Brown-Chidsey, "No more waiting to fail," Educational Leadership, vol. 65, no. 2, pp. 40-46, 2007.

[9] G. Cartledge, A. Singh, and L. Gibson, "Practical behaviormanagement techniques to close the accessibility gap for students who are culturally and linguistically diverse," Preventing School Failure: Alternative Education for Children and Youth, vol. 52, no. 3, pp. 29-38, 2008.

[10] B. Harry and Klingner, "Discarding the deficit model," Educational Leadership, vol. 64, no. 5, pp. 16-21, 2007.

[11] J. J. Venn, Assessing Students with Special Needs, Pearson Education, Inc, Upper Saddle River, NJ, USA, 2007.

[12] S. Barnett, D. Epstein, A. Friedman, R. Sansanelli, and J. Hustedt, The State of Preschool 2009, The National Institute for Early Education Research, New Brunswick, NJ, USA, 2009.

[13] R. Drury, Young Bilingual Learners at Home and School: Researching Multilingual Voices, Trentham Books Limited, Sterling, VA, USA, 2007.

[14] B. Harry and Klingner, Why are so Many Minority Students in Special Education? Understanding Race and Disability in Schools, Teachers College Press, New York, NY, USA, 2006.

[15] E. P. Kritikos, "Speech-Language pathologists' beliefs about language assessment of bilingual/bicultural individuals," American Journal of Speech-Language Pathology, vol. 12, no. 1, pp. 73-91, 2003.

[16] S. J. Kuder, Teaching Students with Language and Communication Disabilities, Pearson Education, Inc, Boston, MA, USA, 2008.

[17] S. Neuman, "Changing the odds," Educational Leadership, vol. 65 , no. 2, pp. 16-21, 2007.

[18] J. Schon, J. Shaftel, and P. Markham, "Contemporary issues in the assessment of culturally and linguistically diverse learners," Journal of Applied School Psychology, vol. 24, no. 2, pp. 163-189, 2008.

[19] J. Abedi, "Assessing English language learners: critical issues," in Cultural Validity in Assessment: Addressing Linguistic and Cultural Diversity, M. del Rosario Basterra, E. Trumball, and G. Solano-Flores, Eds., pp. 49-71, Routledge, New York, NY, USA, 2011.

[20] G. N. Garcia, P. McCardle, and S. M. Nixon, "Prologue: development of English literacy in Spanish-speaking children: 
transforming research into practice," Language, Speech, and Hearing Services in Schools, vol. 38, no. 3, pp. 213-215, 2007.

[21] M. K. Wolf, J. L. Herman, J. Kim et al., Providing Validity Evidence to Improve the Assessment of English Language Learners, The Regents of the University of California, National Center for Research on Evaluation, Standards, and Student Testing (CRESST) Report 738, Los Angeles, CA, USA, 2008.

[22] K. P. Harris, “Speech-language pathologists' professional efficacy beliefs about assessing the language skills of bilingual/bicultural/ bidialectal students," Graduate Theses and Dissertations, vol. A66/03, 2005, http://scholarcommons.usf.edu/etd/1070.

[23] J. K. Klingner and B. Harry, "The special education referral and decision-making process for English language learners: child study team meetings and placement conferences," Teachers College Record, vol. 108, no. 11, pp. 2247-2281, 2006.

[24] A. Bandura, Social Learning Theory, Prentice Hall, Englewood Cliffs, NJ, USA, 1977.

[25] A. Bandura, "Social cognitive theory in cultural context," Applied Psychology, vol. 51, no. 2, pp. 269-290, 2002.

[26] G. I. Becker, Factors affecting the identification of Hispanic English language learners, Doctoral dissertation, Northcentral University, ProQuest Dissertations Publishing, UMI No. 3528919, 2012.

[27] P. Gándara and M. Hopkins, English Learners and Restrictive Language Policies, Columbia University, Teachers College, New York, NY, USA, 2010.

[28] R. J. Skiba, A. B. Simmons, S. Ritter et al., "Achieving equity in special education: history, status, and current challenges," Exceptional Children, vol. 74, no. 3, pp. 264-288, 2008.

[29] A. L. Sullivan, "Disproportionality in special education identification and placement of English language learners," Exceptional Children, vol. 77, no. 3, pp. 317-334, 2011.

[30] S. H. Ochoa, B. D. Rivera, and M. P. Powell, "Factors used to comply with the exclusionary clause with bilingual and limited-English-proficient pupils: initial guidelines," Learning Disabilities Research \& Practice, vol. 12, pp. 161-167, 1997.

[31] E. A. Grassi and H. B. Barker, Culturally and Linguistically Diverse Exceptional Students, Sage, Thousand Oaks, CA, USA, 2010.

[32] J. Shackelford, "State and jurisdictional eligibility definitions for infants and toddlers with disabilities under IDEA," $\mathrm{Na}$ tional Early Childhood Technical Assistance Center, vol. 21, pp. 1-16, 2006.

[33] N. Frederickson and T. Cline, Special Educational Needs, Inclusion and Diversity, McGraw Hill, New York, NY, USA, 2009.

[34] M. Guiberson, "Hispanic representation in special education: patterns and implications," Preventing School Failure: Alternative Education for Children and Youth, vol. 53, no. 3, pp. 167-176, 2009.

[35] D. P. Hallahan, C. E. Keller, E. A. Martinez, E. S. Byrd, J. A. Gelman, and X. Fan, "How variable are interstate prevalence rates of learning disabilities and other special education categories? A longitudinal comparison," Exceptional Children, vol. 73, no. 2, pp. 136-146, 2007.

[36] D. Busch, "Pre-service teacher beliefs about language learning: the second language acquisition course as an agent for change," Language Teaching Research, vol. 14, no. 3, pp. 318-337, 2010.

[37] T. J. Landrum, B. G. Cook, M. Tankersley, and S. Fitzgerald, "Teacher perceptions of the useability of intervention information from personal versus data-based sources," Education and Treatment of Children, vol. 30, no. 4, pp. 27-42, 2007.

[38] F. Tong, L. G. Castillo, and A. Perez, "A psychological profile of acculturation, ethnic identity, and teaching efficacy among
Latino in-service teachers," International Education Studies, vol. 3, no. 3, pp. 41-51, 2010.

[39] C. Granger, Silence in Second Language Learning: A Psychoanalytic Reading, Multilingual Matters, Ltd, Ontario, Canada, 2004.

[40] P. O. Tabors, One Child, Two Languages: A Guide for Early Childhood Educators of Children Learning English as a Second Language, Paul H. Brookes, Baltimore, MD, USA, 2008.

[41] S. Krashen, Explorations in Language Acquisition and Use, Heinemann, Portsmouth, NH, USA, 2003.

[42] W. S. Barnett, D. J. Yarosz, J. Thomas, K. Jung, and D. Blanco, "Two-way and monolingual English immersion in preschool education: an experimental comparison," Early Childhood Research Quarterly, vol. 22, no. 3, pp. 277-293, 2007.

[43] E. E. Garcia and K. P. Scribner, "Latino pre-k-3 education: a critical foundation," in Handbook of U.S. Latino Psychology: Developmental and Community-Based Perspectives, F. A. Villarruel, G. Carlo, J. Grau, M. Azmitia, N. J. Cabrera, and T. J. Chahin, Eds., pp. 267-290, Sage, Thousand Oaks, CA, USA, 2009.

[44] D. Conger, "Does bilingual education interfere with Englishlanguage acquisition?," Social Science Quarterly, vol. 91, no. 4, pp. 1103-1122, 2010.

[45] D. L. Voltz and L. Collins, "Preparing special education administrators for inclusion in diverse, standards-based contexts: beyond the council for exceptional children and the interstate school leaders licensure consortium," Teacher Education and Special Education: The Journal of the Teacher Education Division of the Council for Exceptional Children, vol. 33, no. 1, pp. 70-82, 2010.

[46] V. Buysse, D. C. Castro, and E. Peisner-Feinberg, "Effects of a professional development program on classroom practices and outcomes for Latino dual language learners," Early Childhood Research Quarterly, vol. 25, no. 2, pp. 194-206, 2010.

[47] L. Shidler, "The impact of time spent coaching for teacher efficacy on student achievement," Early Childhood Education Journal, vol. 36, no. 5, pp. 453-460, 2009.

[48] IDEIA, Individuals with Disabilities in Education Improvement Act, 2004, Pub. L. No. 108-446, U. S. Congress, 2004.

[49] R. Marzano, What Works in Schools: Translating Research into Action, ASCD, Alexandria, VA, USA, 2007.

[50] E. E. Garcia and B. Jensen, "Helping young Hispanic learners," Educational Leadership, vol. 64, no. 6, pp. 34-39, 2007.

[51] L. Florian, "Special education in an era of inclusion: the end of special education or a new beginning?," Psychology of Education Review, vol. 34, no. 2, pp. 22-29, 2010.

[52] E. C. O'bryon and M. R. Rogers, "Bilingual school psychologists' assessment practices with English language learners," Psychology in the Schools, vol. 47, no. 10, pp. 1018-1034, 2010.

[53] E. R. Thompson and F. T. T. Phua, "Reliability among senior managers of the marlowe-crowne short-form social desirability scale," Journal of Business and Psychology, vol. 19, no. 4, pp. 541-554, 2005.

[54] E. E. Garcia and B. Jensen, "Early educational opportunities for children of Hispanic origins," Social Policy Report, vol. 23, no. 2, pp. 3-19, 2009.

[55] M. M. Páez, P. O. Tabors, and L. M. López, "Dual language and literacy development of Spanish-speaking preschool children," Journal of Applied Developmental Psychology, vol. 28, no. 2, pp. 85-102, 2007.

[56] E. V. Hamayan, B. Marler, C. S. Lopez, and J. Damico, Special Education Considerations for English Language Learners: Delivering a Continuum of Services, Caslon Publishing, Philadelphia, PA, USA, 2013. 


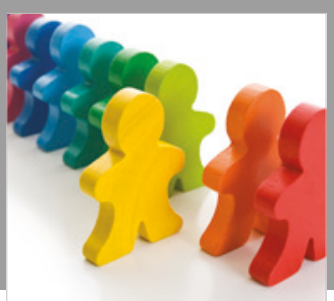

Autism

Research and Treatment
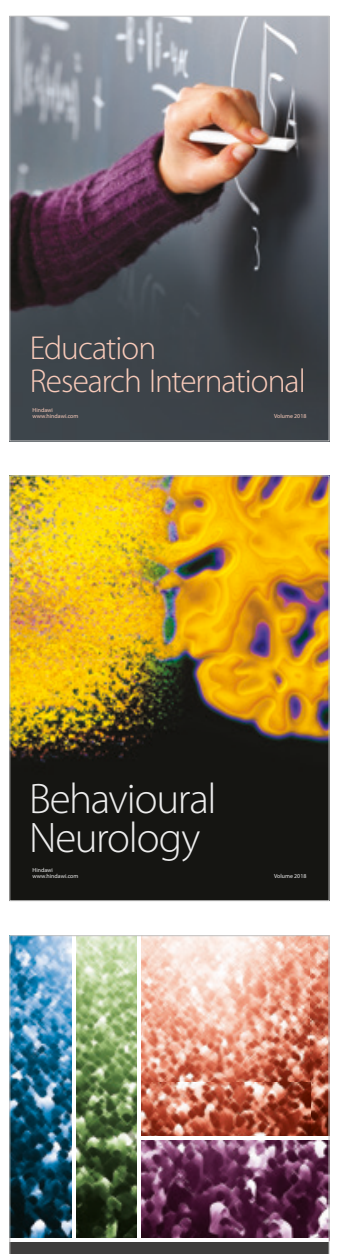

International Journal of

Population Research

$\underline{-m}$

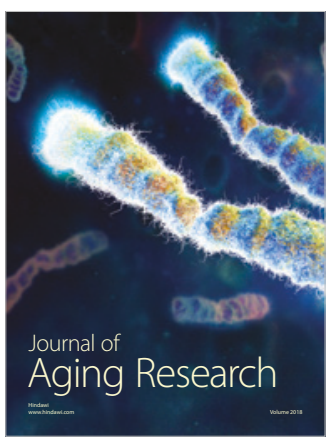

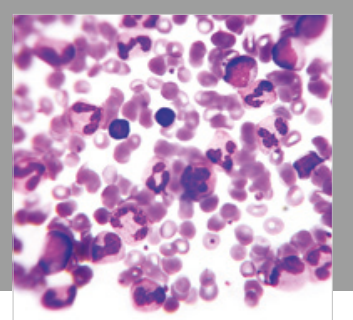

Pathology

Research International$$
=
$$

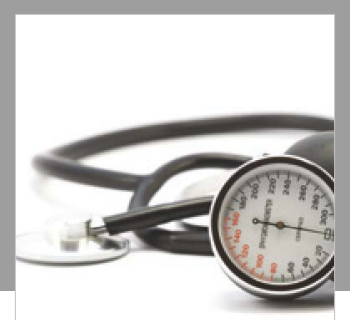

Nursing

Research and Practice



Pain

Research and Management

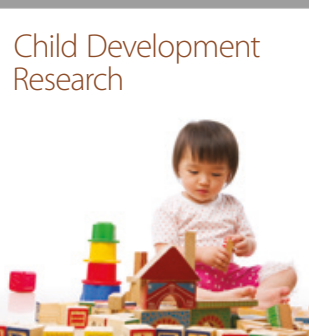

बाD

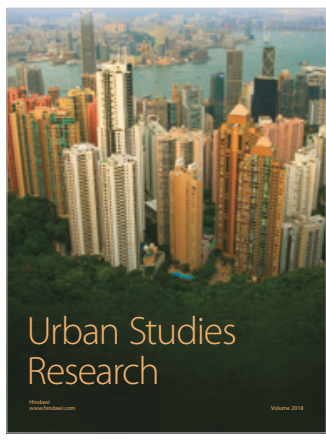

\section{Hindawi}

Submit your manuscripts at

www.hindawi.com
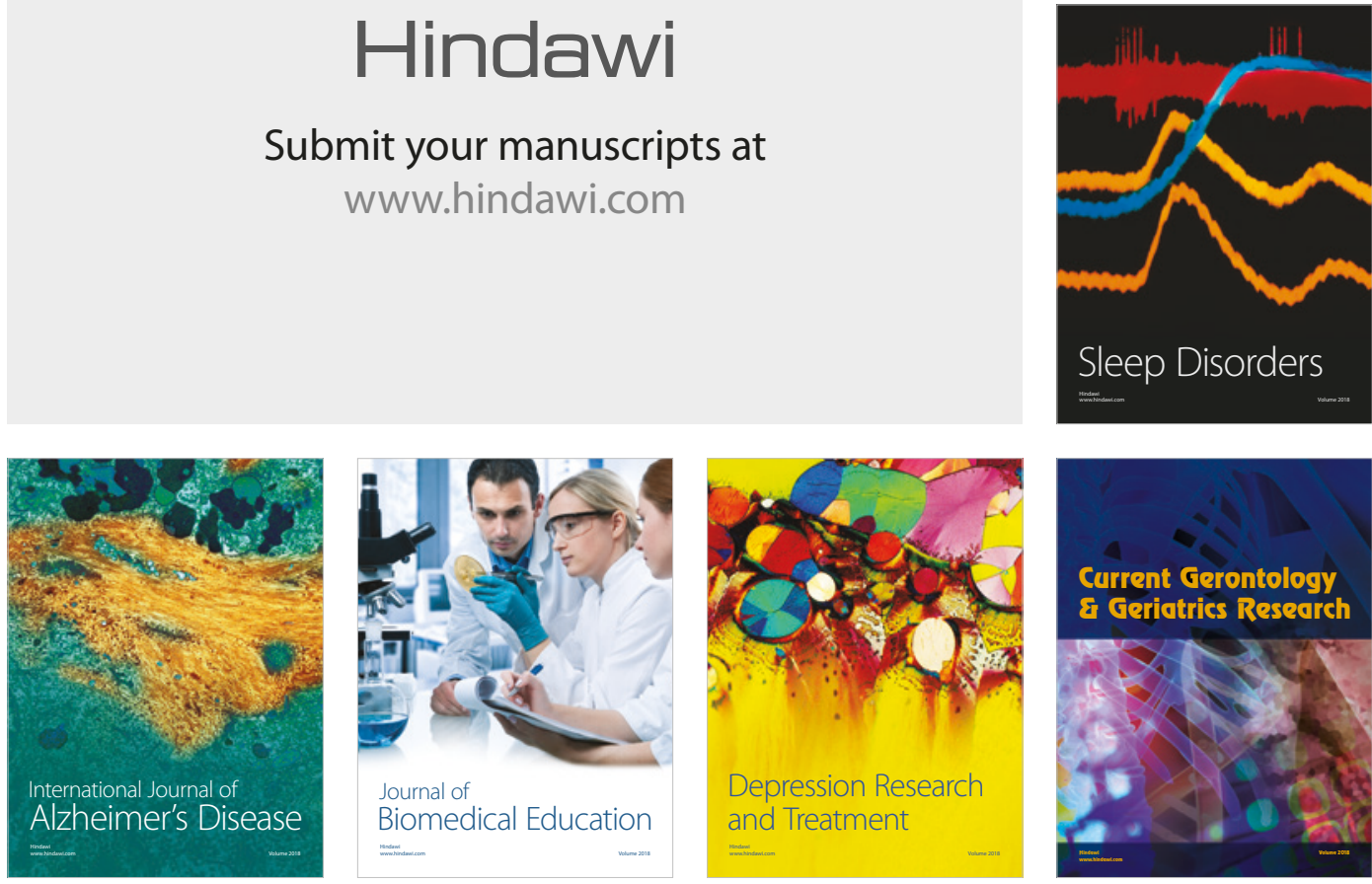

Journal of

Biomedical Education

$=$

smman

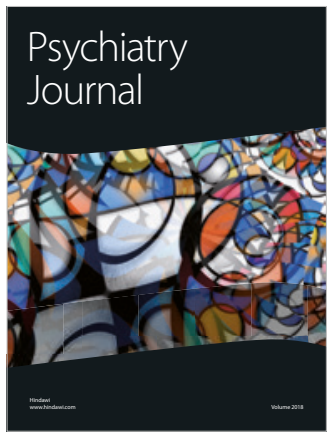

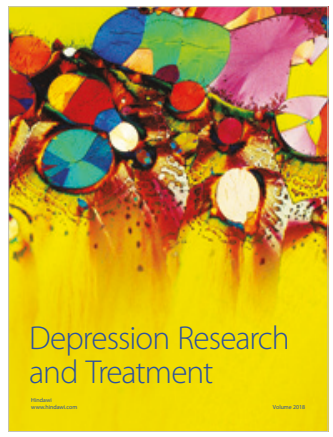
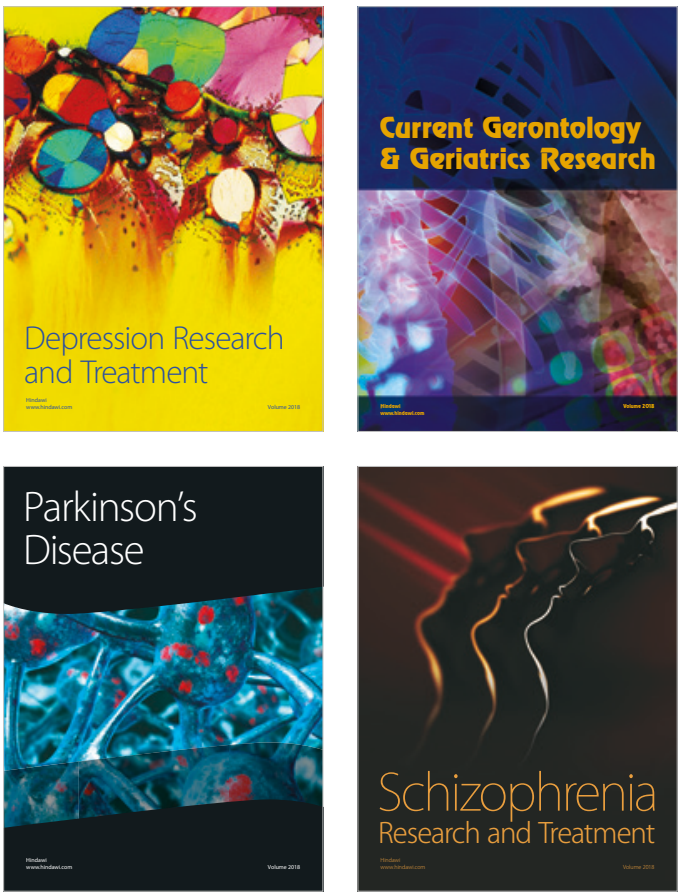